\title{
Las coincidencias del pensamiento de John H. Williams y Raúl Prebisch acerca del orden económico internacional de posguerra
}

\author{
Similarities in John H. Williams' and Raúl \\ Prebisch's Thought about the International \\ Monetary Order in the Postwar
}

\author{
Noemí Brenta* \\ Universidad de Buenos Aires, Buenos Aires, Argentina, email: nbrenta@gmail.com
}

\begin{abstract}
Resumen. Este trabajo indaga en las similitudes del pensamiento de Williams y Prebisch sobre el sistema monetario internacional, y analiza la articulación entre los intereses oficiales estadunidenses y los países periféricos en los albores de Bretton Woods, a través de la interpretación del balance de pagos, compartida por ambos, basada en la teoría de la interdependencia y complementariedad centro-periferia. Prebisch mantuvo un largo vínculo de amistad y trabajo con Williams, profesor de Harvard y vicepresidente del Banco de la Reserva Federal de Nueva York en la época de discusión de los planes monetarios internacionales, e impulsó la industrialización de los países periféricos acorde al nuevo orden económico mundial, bajo la hegemonía estadunidense, y con el capital extranjero como requisito necesario, reflejando el aparato conceptual aquí analizado.
\end{abstract}

Palabras clave: sistema monetario internacional; Fondo Monetario Internacional; dependencia económica.

Abstract. This work explores the similarities in Williams' and Prebisch's thoughts about the international monetary system, and analyzes the conceptual link between the strategic interests of the United States and those of the peripheral countries, through the interpretation of the balance of payments accounts based on the theory of interdependence centre-periphery, in the dawn of Bretton Woods institutions. Prebisch maintained a relationship of work and friendship with Williams, a Harvard professor and vice president of the Federal Reserve Bank of New York when the international monetary plans were discussed, and promoted the industrialisation of peripheral countries according to the new world economic order, under the hegemony of the

* Instituto de Estudios Históricos, Económicos, Sociales e Internacionales, Unidad Ejecutora en Red del Consejo Nacional de Investigaciones Científicas y Técnicas. Universidad Tecnológica Nacional Facultad Regional General Pacheco. Agradezco los valiosos comentarios de los evaluadores anónimos.

Am. Lat. Hist. Econ., may.-ago., 2017, pp. 235-258 | DOI: 10.18232/alhe.v24i2.718 
United States, and based on the foreign capital, putting in practice the theoretical tools here analyzed.

Key words: international monetary system; International Monetary Fund; economic dependence.

Fecha de recepción: 22 de octubre de 2015. Fecha de aceptación: 12 de julio de 2016.

\section{INTRODUCCIÓN}

$\mathrm{E}$ $\mathrm{n}$ el periodo de expansión del capitalismo de la segunda posguerra, entre 1955 y 1975, la concepción del desarrollo alentada en los organismos de las Naciones Unidas -el más importante de ellos en esta temática, la Comisión Económica para América Latina (CEPAL)-, era complementaria del proyecto del Estado de bienestar de los países industrializados (Amin, 1995, p. 1). Teóricamente, las instituciones financieras internacionales del sistema de la Organización de las Naciones Unidas, como el Fondo Monetario Internacional (FMI), las agencias de préstamo del Banco Mundial y los bancos multilaterales, debían facilitar la evolución ordenada de ambos procesos: el bienestar y el desarrollo. Para ello, todos los países debían adoptar el multilateralismo y la liberación del comercio y de los pagos internacionales corrientes a fin de posibilitar la maximización del producto bruto mundial a través de la asignación óptima de las inversiones y de los recursos sociales.

Desde su papel de funcionario principal de la CEPAL, el economista argentino Raúl Prebisch (1901-1986) desplegó una participación articuladora entre los intereses oficiales estadunidenses y los países periféricos, y en especial, su país de origen, a través del impulso al desarrollo sustitutivo de importaciones y del estímulo a las inversiones extranjeras, bajo un esquema de complementariedad virtuosa.

Las relaciones de Prebisch con el gobierno estadunidense durante las décadas de 1930 y 1940, a través de sus contactos con la embajada de Estados Unidos en Buenos Aires, con la Reserva Federal y con economistas de universidades estadunidenses de primera línea, son capítulos de la vida de Prebisch poco conocidos que la biografía elaborada por Dosman (2008) ilumina de manera minuciosa y documentada, aunque pasa por alto buena parte de los vínculos entre el argentino y John H. Williams (1887-1980), profesor y decano de la facultad de administración de Harvard y vicepresidente de la Reserva Federal a cargo de las investigaciones económicas, sus posiciones más destacadas en la década de 1940. Prebisch y Williams compartieron una larga relación de amistad y trabajo, y fuertes semejanzas en sus enfoques de temas teóricos y aplicados. 
Entre los primeros, debemos señalar la interpretación similar de ambos economistas del ajuste del balance de pagos en las economías subordinadas a los ciclos de los países centrales, que Prebisch (1991a y 1991b) publicó en 1921 inspirado en el libro de Williams (1920) Argentine international trade under inconvertible paper money, 1880-1900, este es su vínculo más conocido. Pero la similitud de su pensamiento incluye otros temas, como las críticas a la teoría ricardiana de las ventajas comparativas del comercio internacional; el concepto de países avanzados y países jóvenes (Williams, 1929), equivalente al de centro y periferia, que Prebisch (1991b) aplicó en sus escritos tempranos para caracterizar las relaciones entre Buenos Aires y las provincias del interior, y más tarde extendió a las relaciones internacionales, utilizando en 1944 por primera vez el término periferia en este sentido (Fiszbein, 2011, p. 164).

Asimismo, y aquí reside el foco de este trabajo, ${ }^{1}$ Prebisch contribuyó a apoyar y difundir en América Latina, las ideas de Williams sobre el rediseño del sistema monetario internacional de posguerra y sobre la participación de las instituciones financieras internacionales y del capital transnacional en los países periféricos. Estas ideas se reflejaron también en las concepciones de las políticas para el desarrollo del economista de la CEPAL. ${ }^{2}$

El plan de la moneda clave, de Williams, cobró gran influencia sobre el FMI luego de la muerte de Roosevelt en 1945, y nuevas investigaciones realizadas en la Reserva Federal revelaron que el papel de John H. Williams en el diseño de las finanzas internacionales de la posguerra fue más relevante que lo que se conocía (Asso y Fiorito, 2004). Dada la influencia de Prebisch, desde la CEPAL, sobre el mundo en desarrollo en las décadas de 1950 y 1960, y sobre América Latina, en particular, la coincidencia y vinculación entre las ideas y propuestas de política económica de ambos economistas es relevante para comprender las implicancias para los países periféricos de adherir al orden internacional de posguerra, a través de los organismos nacidos en Bretton Woods, principalmente el FMI. En especial, porque este constituye uno de los dispositivos de influencia y validación de los intereses económicos y estratégicos de Estados Unidos en el mundo ${ }^{3}$ (Stiglitz, 2002, pp. 273-297; Meltzer, 2003, p. 617; Reinhart y Trebesch, 2015, pp. 4, 22 y 28), sobre todo en los países periféricos, sin desconocer

${ }^{1}$ La vinculación entre las ideas de Prebisch y Williams sobre los planes monetarios internacionales fue planteada por primera vez en Brenta (2007; 2012).

${ }^{2}$ Estas ideas también se recogieron en el plan de reformas económicas aplicadas en Argentina por el gobierno militar que depuso a Perón, en 1955, diseñado por Prebisch como asesor presidencial, tema que escapa al alcance de este artículo. Véanse Jauretche (1955) y Brenta (2013, pp. 126-137).

${ }^{3}$ Véase Ley 171 US Code de adhesión de Estados Unidos al FMI y al Banco Mundial. 
la heterogeneidad de tales intereses y las fluctuaciones de su capacidad de presión en diversas épocas.

Ya en la década de 1920, Williams y Prebisch compartían el concepto de que el mundo se organiza en países clave y países jóvenes necesariamente interdependientes. ${ }^{4}$ Los países centrales avanzan a través del cambio tecnológico, y periódicamente desencadenan ciclos que sacuden y desestabilizan a las economías menos avanzadas, que, a su vez, dependen de aquellas para su desarrollo (Williams, 1929, pp. 200-202). Y en la década de 1940 Williams y Prebisch convergieron en un esquema complementario al recomendar medidas de política económica fundadas en este enfoque. Así, Williams (1944b) sostenía que Estados Unidos debía invertir en el exterior para aumentar su prosperidad, y Prebisch (1949) que los países latinoamericanos debían atraer inversiones externas para desarrollarse; para ambos, Estados Unidos debía prestar sus superávits de exportación para que el resto del mundo pudiera comprarles, y Prebisch aconsejaba a los países latinoamericanos importar bienes duraderos y de capital estadunidenses y pedir prestado en el extranjero. Y, puesto que la estabilidad monetaria internacional dependía del pleno empleo en Estados Unidos (Williams, 1944b, p. 379), los países latinoamericanos debían comprender que su propia estabilidad dependía del pleno empleo en Estados Unidos, y apoyarlo (Prebisch, 1944, p. 191).

En el primer apartado de este artículo se refieren los vínculos de amistad y trabajo entre Williams y Prebisch desde 1920, vigentes en la década de 1940, que es el periodo de interés de estas notas; en el segundo, se desarrollan las críticas de Williams a los planes de los gobiernos estadunidense y británico para la reforma del sistema monetario internacional, y su propuesta de sustituirlos por el plan de la moneda clave finalmente adoptado de hecho en 1945; en el tercer apartado, se refieren las opiniones de Prebisch sobre ambas cuestiones, coincidentes con las de Williams; en el cuarto, se identifica el modo en que este pensamiento se reflejó en el documento que Prebisch (1949) preparó para la conferencia de la CEPAL en La Habana, más tarde conocido como Manifiesto (Hirschman, 1961, p. 13), guía de recomendaciones de política económica para los países periféricos en las décadas de 1950 y 1960. Las conclusiones sugieren interpretar esta afinidad entre el gran economista de la CEPAL y el alto funcionario de la Reserva Federal, centrado en los intereses de los banqueros de Nueva York y en la supremacía del dólar, en la brecha aún enigmática de los "dos

${ }^{4}$ Friedrich List (1841) estableció las primeras distinciones jerárquicas entre países: los de clima templado y los de clima cálido, sólo los primeros podían aspirar al desarrollo industrial. Vicente Fidel López, profesor de economía política en 1874-1876, popularizó este enfoque en Argentina, y también Alejandro Bunge, en la Revista de Economía Argentina, en la que Prebisch colaboró en la década de 1920, se refería a países astros y satélites. 
Prebisch”, cuya manifestación más obvia fue su heterodoxia estructuralista en América Latina, y su actuación favorable a los intereses extranjeros en su país de origen, Argentina.

\section{Los vínculos de amistad y trabajo entre Prebisch y Williams}

John H. Williams fue el autor del plan de la moneda clave ${ }^{5}$ para el diseño del sistema monetario internacional de posguerra que algunos autores consideran el modelo efectivamente aplicado en el FMI (Block, 1989, p. 93; Meltzer, 2003, p. 585). Como veremos, Prebisch apoyó y difundió el plan de Williams en el ámbito latinoamericano, en el entorno temporal de la Conferencia de Bretton Woods. Podría pensarse que la adhesión de Prebisch a la opinión de Williams sobre los planes monetarios internacionales provenía de su lectura de los artículos del economista estadunidense publicados en esa época. ${ }^{6}$ Pero hubo una relación más estrecha entre ambos. Prebisch fue amigo y discípulo de Williams desde la década de $1920^{7}$ (Cortés Conde, 2001, p. 85); asimismo, desde su cargo de gerente general del Banco Central colaboró estrechamente con el Banco de la Reserva Federal de Nueva York en el que John Williams revistó entre 1933 y $1950 .^{8}$ El vínculo entre ambos economistas continuó tras la salida de Prebisch del Banco Central en 1943 (Dosman, 2001, pp. 89-105).

El eslabón inicial entre Williams y Prebisch fue Alejandro E. Bunge (1880-1943), director general de Estadística de la Nación y profesor de Prebisch en la universidad. Williams realizó su tesis doctoral sobre la econo-

${ }^{5}$ La historia oficial del FMI (Horsefield, 1969) reconoce cinco planes previos a la versión que llegó a Bretton Woods: Keynes, White, francés, canadiense y el de la moneda clave del profesor Williams. El FMI publicó los cuatro primeros planes completos en su compilación de los documentos previos a la Conferencia de 1944, y el plan de la moneda clave (Horsefield, 1969,vol. III, pp. 119-127), extraído de una antigua presentación de Williams (1936) y de un artículo crítico de los planes White y Keynes (Williams, 1943a).

${ }^{6}$ Las críticas de Williams (1943a; 1944a; 1944b) a los planes monetarios de posguerra se publicaron entre 1943 y 1944 en la revista Foreign Affairs del Council of Foreign Relations, organización de la que este fue director emérito entre 1937 y 1964, y en un libro de Williams (1944c). En el mismo año 1944, las opiniones de Prebisch (1944, 1991c y 1993) sobre los planes monetarios internacionales respaldaron explícitamente las posiciones de Williams.

${ }^{7} \mathrm{La}$ amistad entre Williams y Prebisch también fue testimoniada públicamente por Benjamín Hopenhayn, discípulo y colaborador cercano de Prebisch, cuando presenté la hipótesis del presente trabajo acerca de la vinculación entre ambos economistas, en ocasión del panel compartido como comentaristas del artículo de Pérez-Caldentey y Vernengo (2012).

${ }^{8}$ Williams ingresó al Banco de la Reserva Federal de Nueva York el 1 de mayo de 1933 como experto en asuntos monetarios internacionales, y en 1936 fue designado vicepresidente y director de investigaciones económicas (Asso y Fiorito, 2004). Williams también fue profesor de economía en Harvard, y entre 1937 y 1947 fue decano de Harvard Graduate School of Public Administration. 
mía argentina bajo la dirección del profesor F. W. Taussig. Para ello, estuvo en Buenos Aires entre julio de 1917 y mayo de 1918, ${ }^{9}$ en ese lapso recibió gran apoyo de Bunge en la recolección de las estadísticas para su investigación, que agradeció en el prefacio de su tesis (Williams, 1920, p. III).

A su vez, Bunge vio a Prebisch por primera vez en 1920, en su seminario sobre costo de vida en la Facultad de Ciencias Económicas de la Universidad de Buenos Aires, y "no vaciló en abrirle su estudio y su revista" (Fernández-López, 1991, p. 7). Prebisch fue discípulo y ayudante de Bunge, además de amigo personal de su familia (Dosman, 2008, p. 698).

En 1921 Prebish tradujo y publicó una versión abreviada ${ }^{10}$ del libro de Williams en cinco números de la Revista de Ciencias Económicas, publicación de la Universidad de Buenos Aires, en la que era director por el Centro de Estudiantes; la misma versión fue publicada como folleto en 1922. En esa época comenzaron los vínculos profesionales y personales entre el profesor de Harvard y el economista argentino, que continuaron en el tiempo. La influencia de las ideas de Williams sobre el joven Prebisch acerca del comercio exterior y de los ciclos económicos es conocida, y algo menos la de este último sobre aquel en materia de control de cambios. Sin embargo, las vinculaciones entre estos influyentes personajes respecto a la cuestión de los planes monetarios internacionales aún no han sido estudiadas.

El gobierno militar surgido del golpe del 4 de junio desvinculó a Prebisch del Banco Central en octubre de 1943, de modo que en la última etapa del diseño de las instituciones para el nuevo orden económico internacional, acordado principalmente entre Estados Unidos y Gran Bretaña, el economista argentino completó sus ingresos de profesor universitario con la realización de consultorías y el dictado de seminarios en países latinoamericanos (Dosman, 2008, p. 3803), empezando por México, entre los cuales se encuentran los textos que expresan sus opiniones sobre los planes monetarios internacionales. Las críticas de Prebisch a los planes White y Keynes fueron algo posteriores a las de Williams, compartían su visión teórica del sistema monetario internacional y su apreciación de la realidad económica mundial, explicitaban su apoyo a las opiniones de Williams y a su plan de la moneda clave, y también coincidían en las recomendaciones de política de allí derivadas.

${ }^{9}$ Prebisch llegó a Buenos Aires el 17 de abril de 1918 (Dosman, 2008, p. 199), y Williams retornó a su país desde Buenos Aires en mayo. Aunque ambos coincidieron un corto tiempo en la Capital Federal, y podrían haberse conocido en ese lapso, no hay registro de que ello haya ocurrido.

${ }^{10}$ Para abreviar el libro de Williams, Prebisch eliminó casi todas las notas al pie y dos párrafos del capítulo 1 acerca de cómo concibió su hipótesis principal a partir de las sugerencias de Taussig. 
En el siguiente apartado se sintetizan las críticas de Williams a los planes monetarios internacionales y su propuesta del plan de la moneda clave.

\section{CRÍTICAS DE WiLliamS A LOS PLANES MONETARIOS INTERNACIONALES}

Como vicepresidente del Banco de la Reserva Federal de Nueva York, y director del Council of Foreign Relations, Williams participó en la discusión acerca de los planes monetarios internacionales (Horsefield, 1969, vol. I. Chronicle, p. 33; Meltzer, 2003, p. 619; Williams, 1943a, 1944c). Sus opiniones fueron controvertidas; en 1943 y 1944 en las esferas oficiales estadunidenses -en el Departamento de Estado, en el Tesoro y en la Junta de la Reserva Federal- el plan de la moneda clave no se consideró seriamente, y se intentó acallar a Williams. Pero el Convenio Constitutivo del FMI recogió el concepto de moneda clave, que llamó de amplia aceptación o libre uso, que comprende aquellas más utilizadas para los pagos internacionales y que se negocian más extensamente en los principales mercados cambiarios.

Las versiones definitivas de los planes de reforma del sistema monetario internacional elaborados por funcionarios de los Tesoros de Gran Bretaña (plan Keynes) y de Estados Unidos (plan White) se dieron a conocer oficialmente al público en abril y agosto de 1943, respectivamente. ${ }^{11}$ Las críticas de Williams a ambos planes se publicaron en dos artículos en la revista Foreign Affairs: "Currency stabilization: the Keynes and White Plans" (julio 1943a) y "Currency stabilization: American and British attitudes" (1944a), y una presentación en la Reunión Anual de la American Economic Association el 24 de enero de 1944, "Postwar monetary plans" (1944b), publicada en sus Proceedings. Unos meses después, en junio de 1944, Williams compiló estos tres artículos en su libro Postwar monetary plans and other essays (1944c), donde incluyó un nuevo trabajo sobre sus objeciones a la Declaración Conjunta de Expertos (Williams, 1944d), ${ }^{12}$ y

${ }^{11}$ El gobierno británico publicó el plan Keynes, Proposal for an International Clearing Union como white paper en abril de 1943, y el Tesoro estadunidense imprimió en julio del mismo año el plan White, Preliminary Draft Outline of a Proposal for an International Stabilization Fund of the United and Associated Nations (reproducidos en Horsefield, 1969, vol. III. Documents, pp. 19-36 y 83-97). Versiones anteriores de ambos planes ya habían circulado al interior de los respectivos gobiernos y se habían intercambiado entre ellos, y también fueron enviadas a gobiernos de países aliados.

${ }^{12}$ La Declaración Conjunta de Expertos para el establecimiento de un FMI fue la base del plan para la estabilización monetaria internacional acordado por los gobiernos de Estados Unidos, Gran Bretaña, la URSS, y otros países aliados, tratado en Bretton Woods. Este documento fue producto de un año de discusiones informales que siguieron a la publicación de los planes Keynes 
otros escritos previos sobre cuestiones monetarias, financieras y del comercio internacional.

Williams (1944d, p. XIII- XVII) consideraba que los planes White y Keynes guardaban mayores similitudes que diferencias. En primer lugar, criticaba la pretensión de universalidad del FMI, puesto que los países no eran iguales jerárquicamente, los más grandes debían gozar de mayor poder en la conducción del organismo, y dudaba que un único tipo de organización monetaria y de política comercial fuera aplicable para todos.

En su opinión, el diseño del FMI dejaba demasiado espacio para las divergencias nacionales, y era "demasiado vago en temas esenciales, tal que muy bien podía significar diferentes cosas para diferentes públicos" (1944d, p. XXVII). Aun si el FMI fuera más un medio para expandir el comercio que para lograr la estabilidad monetaria internacional -como se rumoreaba en las altas esferas del poder-, sus recursos serían tan escasos que no podría cumplir esta misión (1944d, p. XXVII). Y, justamente por esa escasez de recursos, los países acumularían reservas por su propia cuenta, y sólo los más débiles recurrirían al organismo. Así, el mundo se desenvolvería en un sistema monetario dual, con algunos países funcionando adentro del fondo y otros fuera de él, condiciones en las que difícilmente se lograría la estabilidad monetaria internacional (1943a, p. 650). Por otro lado, un Fondo Monetario muy grande probablemente llevaría a postergar el ajuste porque proveería un resuello para permitir al país deficitario negarse a tomar medidas correctivas (1944b, p. 376). Al respecto, la principal debilidad de los planes oficiales era su casi completa omisión de mencionar la necesidad de ajuste interno (1944b, p. 377), sino que parecería que el acceso a los recursos sería completamente automático mientras el FMI no incrementara sus tenencias de la moneda del país prestatario en más de $25 \%$ de su cuota durante un año, o aquellas no excedieran el doble de la cuota de dicho país.

Williams (1943a, p. 648) opinaba que el mecanismo monetario de ambos planes era esencialmente el del patrón oro, ya que el valor de las monedas se fijaba en relación con una unidad de cuenta -unitas, según el plan White; o bancor, según el plan Keynes-; las transferencias de monedas en el FMI (White), o los débitos y créditos en la Unión Compensatoria (Keynes), equivalían a los movimientos de oro bajo ese sistema, y afectarían las reservas internacionales de los países y los precios domésticos del mismo

\footnotetext{
y White en abril de 1943, este último en versión abreviada (Horsefield, 1969, vol. I, p. 31). El secretario del Tesoro estadunidense H. Morgenthau hizo pública la Declaración Conjunta el 21 de abril de 1944, y un mes más tarde el presidente Roosevelt convocó formalmente a la Conferencia Monetaria y Financiera de las Naciones Unidas y Aliadas en Bretton Woods.
} 
modo que el patrón oro, sólo que tales efectos podían modificarse por los poderes de ajuste asignados en ambos planes al directorio del organismo.

En este sentido, uno de los grandes defectos de la teoría del patrón oro ha sido, según Williams (1944b, p. 378), su falla en tener en cuenta el ciclo de negocios. El papel de los precios domésticos bajo un tipo de cambio fijo, la esencia de la teoría clásica, no toma en cuenta sus relaciones con las fluctuaciones del producto y del empleo, ya que la teoría del patrón oro da por garantizado el pleno empleo. Pero, continuaba Williams, las relaciones entre los movimientos de capital y las fluctuaciones económicas no sólo generan pánicos financieros, sino que también transmiten auges y depresiones, y se presentan situaciones en las que el auge en un país es alimentado por la deflación en otro, como ocurrió durante la década de 1920, cuando los capitales fluyeron desde Europa hacia Estados Unidos. El tema usualmente abordado ha sido cómo proteger a la economía doméstica de las fuerzas contractivas, o cómo maximizar la expansión a partir de las fuerzas externas expansivas, más que como lograr la estabilización monetaria internacional.

La experiencia británica, afirmaba Williams (1944b, p. 374), mostraba que el patrón oro trabajaba por la contracción en los países deficitarios, más que por la expansión de los superavitarios, por dos razones. Una, la importancia desigual del balance de pagos entre países cuyo comercio exterior y pagos externos son grandes en relación con la economía doméstica, y otros países en los que el comercio exterior es menos importante. La segunda razón es el tamaño diferente de los países. Las prácticas del patrón oro del siglo XIX no operaban sobre el principio de interacción entre países homogéneos, sino sobre el de un centro común con el que los otros países estaban conectados a través del comercio y de las finanzas. Pero no estando en funcionamiento estos principios, el tamaño desigual de los países presentaba problemas con los que el patrón oro no podía lidiar, y Williams no creía que la creación de un organismo internacional que recomendara, o aun impusiera, medidas correctivas, pudiera controlar esta situación (1944b, p. 373).

Un gran superávit de exportaciones u otro cambio que llevara a un ingreso sustancial de oro tendrían probablemente un efecto mucho menos expansivo en Estados Unidos que contractivo en los países deficitarios, observaba Williams. Este efecto desigual de los intercambios internacionales y la peculiar posición de Estados Unidos en este problema lo llevaba a pensar que el principal acreedor y el país más grande del mundo debía tomar la responsabilidad de liderar el esquema de la estabilización cambiaria, asegurando razonablemente su éxito (1944b, p. 374). La estabilidad monetaria y del comercio internacional exigía compromisos basados en el ajuste simultáneo de deudores y de acreedores en condiciones de comer- 
cio predominantemente multilateral, con libre convertibilidad y tipos de cambio estables. Pero estos compromisos tenían diferentes implicancias sobre los distintos tipos de países, y la tarea de proveer el núcleo duro del sistema -esto es, los mecanismos de ajuste simultáneo- debía recaer en los países clave (1944d, p. XVIII).

Asimismo, Williams (1944d, p. XVIII) advertía que los países agrícolas dependían del comercio internacional mucho más que los industriales. Sus ingresos por exportaciones se transformaban en importaciones, o, en tiempos de guerra, en saldos en divisas en el exterior e, internamente, en inflación. Su bienestar dependía fundamentalmente del mantenimiento de los mercados para sus productos en los países avanzados, es decir, de la elevada producción y del empleo en estos últimos. En consecuencia, Williams pensaba que los países jóvenes debían tener especial libertad para variar sus tipos de cambio, comparado con los países más avanzados, para protegerse de las fluctuaciones en los periodos de escasez y para implementar su desarrollo industrial de largo plazo, además, ello no afectaría demasiado a los países más grandes. Los países jóvenes experimentaban sus mayores dificultades cuando el ingreso de capital externo se frenaba bruscamente, afirmaba Williams. Las mismas circunstancias que frenaban el ingreso de capitales reducían los mercados para sus productos y el valor de sus exportaciones, entonces estos países frecuentemente no podían mantener el pago de intereses o siquiera el de sus importaciones. Como la economía de los países jóvenes y su posición de balance de pagos reflejaba más que nada las condiciones de los países más grandes, si estas eran malas, no tenían más remedio que recurrir al control de cambios (1943a, p. 656).

El control selectivo de cambios era, para Williams (1943a, p. 653), un mal menor y, en todo caso, sería útil para atravesar el periodo de escasez del dólar, que sobrevendría en la posguerra. En este tema reconocía la influencia de Prebisch, aunque no mencionaba su nombre y apellido: "Luego de discutir sus problemas con algunos pensantes e inteligentes nativos de tales países, me he convencido de que el control de cambios, si se aplica apropiadamente, es el método más efectivo y que podría presentar menos problemas para los demás países" (p. 20, traducción propia).

Si bien le parecía inevitable que los saldos bloqueados de divisas se canalizaran a través de acuerdos comerciales bilaterales, consideraba que el control selectivo de las importaciones era un instrumento más efectivo, más preciso y más flexible que las tarifas elevadas sobre las importaciones. Esta política está en línea con las recomendaciones de Prebisch, para Argentina y los países periféricos en general, de controlar ciertas importaciones y liberar otras. Con el tiempo, continuaba Williams (1944d, p. $\mathrm{xX}$ ), se podrían eliminar algunos controles y mantener otros, "y la cuestión sería de predominancia de fuerzas, políticas y prácticas en el mundo como 
un todo, y esto depende fundamentalmente de las políticas de los países clave".

A juicio de Williams (1944b, p. 379), la estabilización monetaria era sólo una parte del programa internacional. El plan Keynes también se ocupaba de la política comercial, de las inversiones de mediano y largo plazos, y de la estabilización de los precios de los productos primarios. Pero aun cuando estos temas eran relevantes, lo que importaba aún más en Estados Unidos era el éxito o el fracaso en mantener un ingreso doméstico y un nivel de empleo elevados. El patrón oro enfatizaba la necesidad de sacrificar a unos para salvar a los otros, pero la estabilidad interna a expensas del comercio internacional, o a expensas de otros países, no era una buena respuesta en el largo plazo. En las condiciones de la posguerra, la estabilidad externa debía esencialmente depender de la estabilidad interna en los países más grandes y, especialmente, de la de Estados Unidos. En cuanto al comercio internacional, el superávit de exportaciones era pequeño comparado con el gasto responsable de las fluctuaciones del ingreso y del empleo en Estados Unidos, ${ }^{13}$ donde la estabilidad externa dependía de la estabilidad interna (1944b, p. 379).

Pero, a juicio de Williams (1944b, p. 380), mantener un alto de nivel de producción y de empleo en Estados Unidos en tiempos de paz no era menos complejo que la estabilización monetaria internacional, y el gobierno parecía haber avanzado menos en esto que en el problema monetario internacional. El panorama económico era incierto, Estados Unidos debía desmovilizar y absorber unos 8000000 de trabajadores de las fuerzas armadas, y unos 4000000 más de las industrias de guerra, y al mismo tiempo contraer el presupuesto federal unos 90000 millones por año para retornarlo a las dimensiones de los tiempos de paz, lo que acarrearía presiones deflacionarias una vez atendida la demanda de bienes diferida en tiempos de guerra. Estados Unidos había experimentado la más increíble expansión del producto durante la guerra (1944b, p. 380), y la política fiscal no parecía suficiente para mantener ese elevado nivel de producción, era necesario algo más (1944b, p. 381).

En síntesis, para Williams, puesto que la solución internacional dependía de la solución doméstica de Estados Unidos, y que esta presentaba numerosas incertidumbres, la adopción de los planes monetarios interna-

${ }^{13}$ Williams (1944b) ejemplifica la irrelevancia del superávit comercial externo para la economía estadunidense: "En 1919, un año en el que el superávit de exportaciones fue inusualmente grande, este fue de 3.7 mil millones contra un gasto agregado de 22.5 mil millones en consumo e inversión [...] en el primer año después de la guerra el superávit neto de exportaciones será de 7 mil millones contra un gasto agregado de 42 mil millones" (p. 54). Pero si se calcula el coeficiente del superávit como porcentaje del gasto agregado, el resultado es $16.4 \%$, guarismo que a todas luces no parece irrelevante. 
cionales parecía prematura, por lo que aconsejaba adoptar el enfoque de la moneda clave. Este consistía en postergar la creación del FMI hasta tanto se estabilizaran las monedas que él consideraba clave: el dólar estadunidense y la libra esterlina y, en menor medida, el franco francés. Williams (1943a, p. 657) sugería que Estados Unidos otorgara un gran préstamo de estabilización a Gran Bretaña, y que ambos países firmaran un acuerdo monetario en el que fijaran sus nuevas paridades cambiarias, las que no podrían modificarse sin previa consulta, mientras que los bancos centrales de ambas naciones compraran la moneda del otro país que les fuera requerida, en montos específicos y con garantías contra pérdidas. Este acuerdo incluiría gradualmente mayor cantidad de monedas, una vez que sus valores se alinearan con la paridad de poder adquisitivo en términos de las divisas clave.

Como veremos, Prebisch apoyó estas posiciones, las difundió en Argentina y en América Latina, en especial en México, y las incluyó en sus propuestas desde la CEPAL para el desarrollo de los países latinoamericanos, y en sus recomendaciones de política económica para la Argentina posperonista.

\section{CRíticas de Prebisch a los Planes monetarios INTERNACIONALES}

Prebisch se refirió a los planes de reforma del sistema monetario internacional durante 1944 en reuniones informales, seminarios y clases, en México y Buenos Aires, y sus disertaciones se difundieron en tres publicaciones en el mismo año, sin contar su reproducción en otros medios ni las compilaciones posteriores.

En orden cronológico, el primer escrito de Prebisch de difusión del tema fue Observaciones sobre los planes monetarios internacionales, que es la "versión de una charla informal tenida en México, en el mes de febrero, con un grupo de economistas mexicanos" (Prebisch, 1944, pp. 185-208), publicada en el Ciclo de conversaciones en el Banco de México S. A. ofrecidas por Raúl Prebisch entre el 24 de enero y el 7 de marzo de 1944, tomo III, como el opúsculo La política monetaria nacional y los planes monetarios internacionales y en El Trimestre Económico.

Unos días después, el 27 de marzo, Prebisch presentó su ponencia "El patrón oro y la vulnerabilidad económica de nuestros países" (1991) en un seminario de El Colegio de México cuyo Centro de Estudios Sociales lo publicó simultáneamente como el primero de una serie relacionada con este seminario; este trabajo se reimprimió también en marzo del mismo año en Buenos Aires, y en julio en Uruguay. Finalmente, las opiniones de Prebisch sobre Los planes monetarios internacionales (1993) también fueron 
expresadas en sus clases dictadas en 1944, luego de la Conferencia de Bretton Woods, en la Facultad de Ciencias Económicas de la Universidad de Buenos Aires.

Para comprender la trascendencia de la participación de Prebisch en la discusión de los planes monetarios internacionales en México, es preciso recordar que este país tuvo un papel único entre las naciones en desarrollo en las instituciones que nacerían en Bretton Woods. ${ }^{14}$ Como prueba de ello, su secretario de Hacienda y Crédito Público, Eduardo Suárez, presidió una de las tres comisiones de la Conferencia de Bretton Woods, la dedicada a otras formas de cooperación financiera internacional; mientras que Harry White y John M. Keynes encabezaron las comisiones para el FMI y el Banco Internacional de Reconstrucción y Fomento, respectivamente. Asimismo, en 1942 el joven economista mexicano Víctor L. Urquidi recibió de Harry White el primer borrador de la propuesta estadunidense de reorganización de la moneda y finanzas mundiales, que se discutiría en reuniones posteriores. ${ }^{15}$

En líneas generales, y en coincidencia con las opiniones de Williams referidas más arriba, Prebisch consideraba que el sistema cambiario previsto en los planes estadunidense y británico -consistente en tipos de cambio fijos ajustables sólo en determinadas condiciones y con la autorización del organismo a crearse- era excesivamente rígido para los países periféricos, cuyo balance de pagos dependía cíclicamente de la evolución de los países centrales. Por esta misma razón, como sostenía Williams, hubiera preferido que los acuerdos monetarios se celebraran entre las principales potencias mundiales, y que se permitiera un ajuste cambiario más flexible en los demás países, cuyo limitado porte no afectaba verdaderamente al sistema monetario internacional.

La flexibilización del sistema cambiario en los países periféricos, afirmaba Prebisch, les permitiría reducir su vulnerabilidad a los ciclos externos que el patrón oro desencadenaba y la tendencia de los centros financieros a cortar los préstamos en épocas de penuria financiera y a expandirlos en las de holgura. En la etapa recesiva del ciclo, las importaciones debían reducirse a través del aumento del tipo de cambio. Por eso, consideraba preferible la posibilidad de modificar los tipos de cambio a la de utilizar incondicionalmente los recursos del organismo, y proponía dividir este acceso en dos partes, la primera incondicional y la segunda condicionada a

\footnotetext{
${ }^{14}$ Para un análisis histórico de la participación de México en la Conferencia de Bretton Woods y en las discusiones previas, véase Turrent Díaz (2009).

${ }^{15}$ White entregó este documento a Urquidi en la cena de clausura de la Conferencia Interamericana sobre Control Financiero y Monetario del Enemigo, celebrada en Washington en junio de 1942 .
} 
la adopción de medidas de política monetaria negociadas con el FMI (1944, p. 204). En este punto también coincidía con Williams.

Según Prebisch (1944, pp. 186-189), los exiguos montos de crédito previstos en el plan White eran insuficientes para asegurar el cumplimiento de las reglas de juego del sistema monetario propuesto, que básicamente consistían en que el país con superávit exportador prestara al resto del mundo para que este pudiera importar, y que estas reglas no se cumplieron en el periodo de entreguerras porque en Estados Unidos, el país superavitario líder, el comercio exterior era muy poco importante en relación con el tamaño de la economía, por ende, los mecanismos monetarios del comercio exterior -la contracción o expansión monetaria a causa de déficits o superávits del balance de pagos- no lo afectaban, pero sí a los países periféricos. Entonces, era fundamental para el resto del mundo que Estados Unidos tuviera pleno empleo (Prebisch, 1944, p. 191) a fin de impulsar la demanda de exportaciones de los demás países. Es notable la semejanza de todo lo referido con el pensamiento de Williams analizado en el apartado anterior. Por ello, continuaba Prebisch, las instituciones financieras internacionales planeadas debían proveer volúmenes de financiamiento significativos, tal como proponía el plan Keynes, ya que la única forma en que Estados Unidos podía aplicar su exceso de exportaciones era comprando o gastando en el exterior. Si la demanda estadunidense de importaciones del resto del mundo fuera insuficiente, Prebisch (1993, p. 199) pronosticaba un periodo de aislamiento similar al de entreguerras: "¿đqué quedará a los otros países? [... ] desarrollarse hacia adentro ya que no es posible desarrollarse hacia afuera" (Prebisch, 1993, p. 108).

Sin embargo, continuaba Prebisch (1944, p. 192), en Estados Unidos existía preocupación porque se suponía que la expansión de la demanda después de la guerra y la disposición de los saldos en divisas en poder de países como México y Argentina, dispararían la inflación, entonces el plan de Keynes tampoco era aplicable en lo inmediato, porque expandiría demasiado el crédito, favoreciendo la inflación: "Y se me ocurre pensar si la solución más conveniente no estará dentro de los lineamientos trazados por el profesor Williams, de la Reserva Federal, quien sostiene que lo mejor, en materia de compromisos relativos al valor de la moneda, sería procurar el entendimiento entre las grandes potencias." (Prebisch, 1944, p. 207). Asimismo, "Williams cree que mejor que estos planes elaborados hubiera sido que los principales países se pongan de acuerdo entre ellos [...] sobre planes de plena ocupación" (Prebisch, 1993, p. 111). 


\section{Williams, Prebisch y el Manifiesto del Desarrollo}

Como se ha visto en los apartados anteriores, aplicadas a los distintos auditorios a los que se dirigían -Williams, al gobierno estadunidense y al establishment financiero neoyorquino; Prebisch, a los gobiernos de los países periféricos y sus clases dirigentes, y ambos a los académicos-, las opiniones de ambos economistas sobre el orden monetario internacional de la posguerra coincidían en un todo, y convergían en un mismo interés: la necesidad axiomática de mantener el pleno empleo en Estados Unidos, y el dólar como moneda clave para los pagos internacionales, con la libra esterlina en segundo término. ${ }^{16} \mathrm{~A}$ juicio de ambos economistas, puesto que el desarrollo de los países jóvenes dependía de la marcha de los países centrales, el pleno empleo en Estados Unidos debía ser también el objetivo de aquellos, por su propio bien.

Examinar un poco más algunas ideas de Williams y Prebisch corrobora lo dicho. Williams interpretaba el desarrollo del comercio internacional como un proceso de expansión desde un centro, que afectaba profundamente el desempeño económico de los países menos avanzados. Los países clave desempeñaban un papel preponderante en la determinación de los ciclos internacionales y de las tendencias de largo plazo. Los periodos de crecimiento y de depresión generalmente se originaban en los países centrales, asociados al cambio tecnológico, mientras que el desarrollo de los demás dependía del movimiento de factores así como de los bienes de capital provenientes del centro. Williams pensaba que el establecimiento de una red de países periféricos era indispensable para la supervivencia del centro porque proveían mano de obra barata y una demanda estable para las exportaciones de los países tecnológicamente más avanzados. Por su parte, Prebisch también consideraba que el centro se apropiaba de los aumentos de productividad de los factores en los países periféricos, y proponía modificar su estructura productiva a través de la industrialización para atenuar sus efectos negativos sobre el desarrollo.

En la visión de Williams, las inversiones externas directas estimulaban un crecimiento más rápido de la productividad en el país prestamista que en el país prestatario, y de ese modo acentuaban las disparidades en los patrones de crecimiento. En este sentido, Williams sostenía que el crecimiento de las inversiones directas estadunidenses en la década de 1920 había contribuido significativamente a la expansión de la economía estadunidense estableciendo un círculo virtuoso: retornos crecientes, márgenes de

${ }^{16}$ Este esquema de monedas clave remite al del Acuerdo Tripartido de 1936 entre Estados Unidos, Gran Bretaña y Francia, en cuyo diseño Williams intervino como funcionario de la Reserva Federal. 
beneficio más elevados y el establecimiento de una red más eficiente de capacidad productiva que, a su vez, motivaba a realizar nuevas inversiones. Así, otorgar préstamos internacionales significaba promover la prosperidad de Estados Unidos. Williams proveía argumentos para apoyar la expansión estadunidense en el exterior, resistida por quienes pensaban que Estados Unidos no debía malgastar sus recursos presupuestarios en aventuras internacionales y temían una nueva ola de antiamericanismo. Williams era un internacionalista que representaba los intereses de los banqueros de Nueva York -tradicionales prestamistas y agentes financieros de los países periféricos- y de los sectores más transnacionalizados de la economía estadunidense.

Por su parte, del concepto fundamental centro-periferia, equivalente al de países clave y países jóvenes de Williams, Prebisch infirió el resto de sus análisis y recomendaciones: la tendencia al deterioro de los términos del intercambio; la inflación estructural y el desempleo; el imperativo de la industrialización, y la necesidad de conformar un mercado común para el desarrollo de América Latina. Estas ideas no importaron una ruptura o un desafío a la hegemonía estadunidense -inviable desde un organismo cuyo presupuesto se negocia en Washington ${ }^{17}$-, sino que reconocieron la especificidad del subdesarrollo y formularon propuestas para mejorar estructuralmente las economías periféricas, al tiempo que presentaron al capital extranjero -préstamos e inversiones- como requisito imprescindible del desarrollo, en un esquema de complementariedad necesaria.

Este concepto de complementariedad entre periferia y centro, que Williams y Prebisch consideraban beneficiosa para los países clave y necesaria para el desarrollo de los periféricos, también se reflejó en el documento El desarrollo económico de América Latina y algunos de sus principales problemas, que el economista argentino (1949) preparó para la Conferencia de la CEPAL en La Habana el 29 de mayo de 1949, y que sirvió de guía y fundamento a las políticas económicas en el mundo periférico durante más de una década.

Por una parte, Prebisch (1949, p. 351) afirmaba que se necesitaban dólares para importar, pero estos eran escasos porque Estados Unidos importaba poco en relación con sus exportaciones, circunstancia que cambiaría en la medida en que el país del norte conservara o llegara al pleno empleo, porque entonces necesitaría importar cada vez más y, por ende, suministraría más dólares al mundo. Por otra, continuaba Prebisch, aunque las

\footnotetext{
${ }^{17}$ Los ingresos de la CEPAL provienen del presupuesto ordinario de la Organización de las Naciones Unidas financiado con cuotas de los Estados miembros, entre los cuales Estados Unidos es el principal aportante, $y$ de fondos extrapresupuestarios que se asignan usualmente a proyectos determinados aportados por Estados miembros, programas y fondos de la Organización de las Naciones Unidas y otras organizaciones y organismos (www.cepal.org).
} 
inversiones extranjeras eran necesarias para el desarrollo, como requerían divisas para ser remuneradas, se debía atraer a aquellas que pudieran sustituir importaciones. Pero, para evitar el excesivo fraccionamiento de los mercados, no debían crearse industrias iguales en los países de América Latina, sino que debía fomentarse la especialización y la integración (1949, p. 357).

A semejanza de la opinión de Williams, ya citada, acerca de la aceleración del crecimiento de la productividad en los países centrales causada por sus inversiones en los periféricos, pero enfocado desde estos últimos, Prebisch (1949, p. 362-369) advertía que mientras que los ingresos de los factores productivos en los países desarrollados crecieron más que la productividad de los factores, en los países periféricos crecieron menos que la productividad, entonces los países desarrollados gozaban de los frutos de su propio progreso técnico y también recibieron parte del fruto del progreso técnico de los países en desarrollo. Esto se debía a los ciclos: en la fase creciente la demanda excedía a la oferta, y el aumento del beneficio hacía subir los precios como modo de cercenar la demanda; los productos industriales aumentaban de precio y ello impactaba en las importaciones de los periféricos, pero los precios de los productos primarios subían y bajaban con mucha mayor rapidez en las fases ascendentes y descendentes del ciclo económico. Los trabajadores industriales de los países centrales estaban en condiciones de defender sus ingresos mucho más firmemente que los que producían bienes primarios, por eso el centro podía trasladar a la periferia el costo de la reducción de beneficios en la fase descendente del ciclo. Así, Prebisch (1949, p. 370) consideraba que la industrialización era el único medio del que disponían los países de América Latina para aprovechar las ventajas del progreso técnico.

Sin embargo, la industrialización recomendada limitaba el desarrollo de las industrias de tecnología más avanzada, las de bienes de capital y de consumo duradero, o las sujetaba a la participación de capital extranjero:

Habiendo mucho campo disponible para aumentar la productividad de las actividades destinadas al consumo corriente, no se advierte qué razón económica habría para [...] forzar la creación de industrias de capital [que se deberían seguir importando a menos que surgieran del propio proceso de desarrollo.] [Y] parecería conveniente importar los artículos de consumo duradero en la medida en que pueda hacerse con exportaciones, o en su caso, con inversiones extranjeras en lo que respecta a los bienes de capital, dentro de un programa general de desarrollo económico (Prebisch, 1949, pp. 430-431).

A pesar de la escasez de dólares, el economista tucumano desaconsejaba importar desde Europa porque era más caro, de manera que cf. 
Prebisch (1949, p. 393) el comercio multilateral era lo más conveniente para el desarrollo de América Latina, para poder comprar y vender en los mejores mercados. Justamente el multilateralismo fue la estrategia internacional conveniente a la indiscutible hegemonía estadunidense, asegurada durante la segunda guerra a través de negociaciones para lograr el compromiso de desmantelamiento de las preferencias imperiales por parte de los países europeos que poseían colonias o territorios controlados, principalmente Gran Bretaña. ${ }^{18}$

Volviendo al Manifiesto, y nuevamente en coincidencia con Williams, Prebisch (1949, p. 395) afirmaba que la escasez de dólares se aliviaría "si Estados Unidos consiguiera mantener su ocupación máxima, y si el resto del mundo, estimulado de este modo por el centro principal, lograra también aplicar una política análoga de plena ocupación de sus factores productivos en crecimiento".

Sin embargo, continuaba Prebisch (1949, pp. 397-398), la plena ocupación del resto del mundo no era factible a través de la movilización autónoma de los recursos propios de los países, sino que, como ya el consumo de las masas era bajo, no se podía crear ahorro y nuevo capital comprimiéndolo, sino que era necesario atraer inversiones extranjeras. De esta manera, las entidades internacionales de préstamos podrían contribuir al desarrollo de los países latinoamericanos facilitando la importación de bienes de capital (Prebisch, 1949, p. 423) y facilitando préstamos en las fases bajantes, como política anticíclica.

Siguiendo estas recomendaciones, en la década de 1950 los gobiernos latinoamericanos favorecieron la recepción de inversiones externas directas, y el flujo de capital estadunidense creció de 3000 millones de dólares en 1946, a 8700 millones en 1958 (O’Brien, 1999, p. 125), aunque América Latina continuó siendo una región de importancia menor para la política externa del hegemón. El grueso de estas inversiones se destinaron al petróleo y, en segundo término, a la industria manufacturera -automóviles, químicos y maquinaria eléctrica, en particular, heladeras- y a los servicios públicos (véase cuadro 1).

Mientras se tratara de un proceso bajo control, desarrollar el mercado interno a través de la industrialización sustitutiva de importaciones liberaba la balanza comercial del balance de pagos en favor de la balanza de

${ }^{18}$ Ya en la Carta del Atlántico, de 1941, en ocasión de la firma del Tratado de Préstamo y Arriendo con Gran Bretaña, este país se comprometió a que al final de la guerra todos los países tendrían libertad de comercio y de acceso a los mercados de materias primas, esto equivalía a su compromiso de futura adhesión al multilateralismo y el fin de las restricciones comerciales y monetarias de la zona de la libra esterlina. La cláusula del multilateralismo también estuvo presente en los convenios de préstamo y arriendo que suscribió Estados Unidos con diez países aliados, además de Gran Bretaña. 


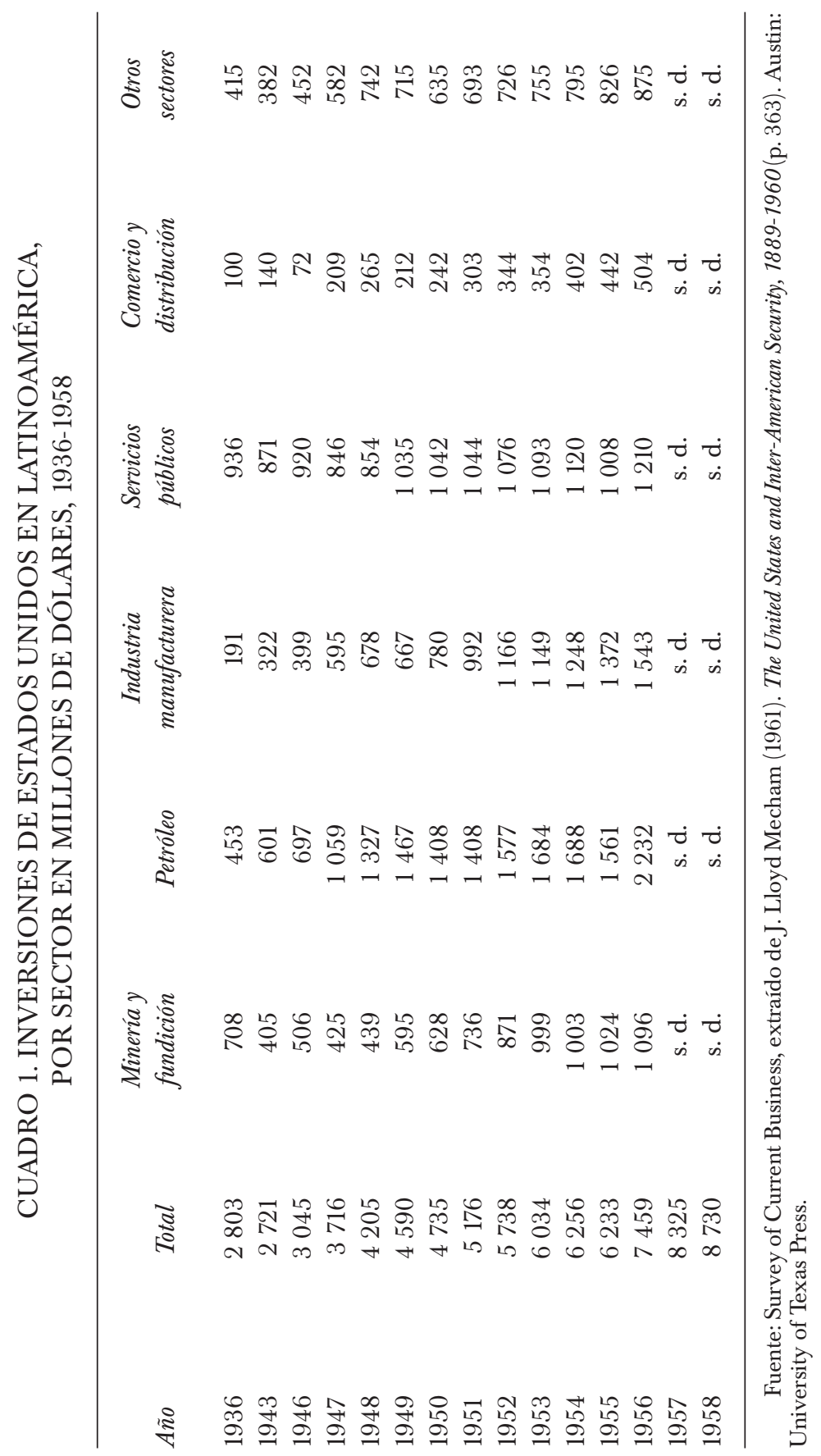


servicios para remunerar las inversiones extranjeras y, al mismo tiempo, mejoraba el nivel de vida de estos países, alejándolos de la amenaza comunista. Todo era ganancia. Sin embargo, desde una visión crítica, Halperin Donghi (1993, p. 202) afirma que la mayor parte de estas inversiones consistió en bienes de capital, en muchos casos maquinarias usadas ya obsoletas o que habían sido reemplazadas por nuevos equipos más eficientes o que satisfacían mejor el apetito de novedades en un mercado más competitivo. Y que una vez establecidas en Latinoamérica, las empresas extranjeras gozaron de crédito doméstico y de los beneficios de ingeniosos acuerdos financieros, tales como el pago adelantado por bienes a ser entregados posteriormente, y que pudieron vender sus productos a precios más elevados que en sus países de origen. Justamente, uno de los atractivos de la inversión externa directa en países periféricos es su rentabilidad mucho más elevada que la obtenida en idénticos sectores en los países más avanzados (Arendt, 1968, p. 269) y la apropiación del aumento de la productividad en los periféricos por parte de los países centrales, como señalaban los análisis de Williams y Prebisch.

\section{CONCLusiones}

La adhesión de Prebisch a las ideas de Williams sobre el orden monetario internacional de posguerra, su convicción de que el crecimiento y pleno empleo de Estados Unidos eran clave para los países periféricos, y la adjudicación de un papel indispensable al capital extranjero en los procesos de desarrollo, complementaria de la idea de Williams de la necesidad de los países centrales de invertir en los periféricos, este conjunto de conceptos compartidos por ambos economistas, podrían sugerir que Prebisch desempeñó un papel de articulador o puente entre los intereses estadunidenses y los de los países periféricos, enarbolando el argumento de ganancias para ambos.

Este análisis no pretende menoscabar al gran economista argentino, sino contribuir a comprender la tantas veces señalada oposición entre las ideas progresistas para el desarrollo que acompañaron su desempeño como secretario ejecutivo de la CEPAL y, por otro lado, su actuación en Argentina ligado a gobiernos autoritarios e inclinados hacia los intereses extranjeros, como en la llamada década infame de 1930-1943, en la que fue subsecretario de Hacienda del gobierno militar que dio el primer golpe de Estado en Argentina, luego asesor de los ministros de Hacienda y de Agricultura, gerente general del Banco Central -en cuya creación tuvo una participación destacada- y en 1955-1956 asesor presidencial y autor del 
plan económico de un gobierno militar que desplegó enorme violencia ${ }^{19}$ antes y después de deponer a Perón. Es decir que se intenta comprender la unidad del pensamiento del economista, y parece plausible que la vinculación intelectual e institucional entre Prebisch y Williams contribuya en este sentido.

Decía Aristóteles en su Poética que para dar el ejemplo la historia debe mostrar a los hombres ejemplares algo más buenos de lo que fueron, y a los enemigos algo más malos. Pero la ciencia debe buscar el conocimiento sin idealizaciones, tabúes o vacas sagradas.

Es cierto que el establishment estadunidense y los organismos financieros internacionales criticaron a la CEPAL porque consideraban que sus argumentos alimentaban el antiamericanismo y la disconformidad de los países en desarrollo y por sus posiciones heterodoxas, ${ }^{20}$ pero siempre la contienda se mantuvo del lado occidental de la guerra fría. Prebisch nunca propuso cruzar la línea, como lo demuestran sus fluidas relaciones con el poder financiero internacional, por ejemplo, el encargo que le hiciera el presidente Kennedy en 1961 para conformar la Alianza para el Progreso, así como las tibias posiciones de la CEPAL respecto de la transferencia de tecnología y de la industrialización sustitutiva como modo de generar divisas para remunerar la inversión. En todo caso, el pecado es de ambigüedad, claro que cuando se compara con el duro tratamiento recibido por los países en desarrollo desde mediados de la década de 1970, la prédica de la CEPAL de las décadas de 1950 y 1960 suena como un coro de ángeles.

\section{LISTA DE REFERENCIAS}

Amin, S. (abril, 1995). Fifty years is enough! Monthly Review, 46(11), 8-50. DOI: 10.14452/ MR-046-11-1995-04

Arendt, H. (1968). Los orígenes del totalitarismo. 2. Imperialismo. Madrid: Alianza.

Asso, P. F. y Fiorito, L. (febrero, 2004). A scholar in action in interwar America. John H. Williams' contributions to trade theory and international monetary reform (Documento de trabajo núm. 430/2004). Italia: Università degli Studi di Siena. DOI: 10.2139/ ssrn.757769.

${ }^{19}$ El 16 de junio de 1955, antes del golpe del 16 de septiembre, la Fuerza Aérea bombardeó la zona de Plaza de Mayo para tratar de asesinar a Perón, matando más de 300 civiles que circulaban por allí; un año después el gobierno del general Aramburu fusiló a militares y civiles en rebelión y emprendió una brutal persecución de sus opositores.

${ }^{20}$ Prebisch comentó en una entrevista que Paul Schweitzer, director gerente del FMI, le dijo que él era considerado "el diablo en persona", pero que conociéndolo mejor, sus ideas no eran como se las habían pintado. Pollock, Kerner y Love (2001). 
BLOCK, F. L. (1989). Los orígenes del desorden económico internacional: la política monetaria internacional de los Estados Unidos, desde la Segunda Guerra Mundial hasta nuestros días (1a. ed. en inglés 1977). México: Fondo de Cultura Económica.

BRenta, N. (2007). El rol del FMI en el financiamiento externo de la Argentina y su influencia sobre la política de ajuste del balance de pagos entre 1956 y 2006 (Tesis doctoral). Universidad de Buenos Aires, Argentina.

Brenta, N. (2012). El pensamiento compartido de John H. Williams y Raúl Prebisch acerca del orden económico internacional de posguerra y su aplicación al ingreso de la Argentina al FMI. Conferencia sobre América Latina presentada para la European Society for the History of Economic Thought (ESHET), Core and periphery: lessons from economic history and the history of economic thought. Buenos Aires (Argentina), 21-23 de noviembre, 1-23.

Brenta, N. (2013). Historia de las relaciones entre Argentina y el FMI. Buenos Aires: Eudeba.

Cortés, R. (diciembre, 2001). Raúl Prebisch: his years in government. Revista de la CEPAL, 75, 81-85. Recuperado de http://hdl.handle.net/11362/10837

Dosman, E. (diciembre, 2001). Los mercados y el Estado en la evolución del "manifiesto" de Prebisch. Revista de la CEPAL, 75, 89-105. Recuperado de http://hdl.handle. net/11362/10777

Dosman, E. (2008). The life and times of Raúl Prebisch, 1901-1986 (edición digital). Canadá: McGill-Queen's Press.

FErnández-López, M. (1991). Nota preliminar. En G. Weimberg (supervisor) y M. FERnÁNDEZ-LóPez (comp.), Raúl Prebisch: Obras, 1919-1948 (v. I, pp. XI-XV). Buenos Aires: Fundación Raúl Prebisch.

FiszBein, M. (julio-septiembre, 2011). Vulnerabilidad externa y desarrollo. Los aportes de Prebisch al desarrollo económico. Ensayos Económicos, 63, 149-194. Recuperado de http://www.bcra.gov.ar/Institucional/Resumen.asp?id=294\&idarchivo=0\&pre vPage $=1$

Halperin, T. (1993). The contemporary history of Latin America. Estados Unidos: Duke University Press.

Hirschman, A. (1961). Ideologies of Economic Development in Latin America. En A. Hirschman (comp.), Latin American Issues: Essays and Comments. Estados Unidos: Twentieth Century Fund.

Horsefield, J. K. (ed.) (1969). The International Monetary Fund, 1945-1965: Twenty years of international monetary cooperation (3 vols.). Washington: International Monetary Fund.

Horsefield, J. K. (ed.) (1969). The International Monetary Fund, 1945-1965: Twenty years of international monetary cooperation. I: Chronicle. Washington: International Monetary Fund.

Horsefield, J. K. (ed.) (1969). The International Monetary Fund, 1945-1965: Twenty years of international monetary cooperation. III: Documents. Washington: International Monetary Fund. 
Jauretche, A. (1955). El Plan Prebisch: retorno al coloniaje. Buenos Aires: Ediciones El 45.

List, F. (1841/1856). National system of political economy (trad. de G. Matile). Filadelfia. Recuperado de https://ia800302.us.archive.org/26/items/nationalsystemp00colwgoog/nationalsystemp00colwgoog.pdf

Meltzer A. H. (2003). A history of the Federal Reserve. Vol. 1. 1913-1951. Chicago/Londres: The University of Chicago Press.

O'Brien, T. (1999). The century of U.S. capitalism in Latin America. Estados Unidos: University of New Mexico Press.

Pérez-Caldentey E. y Vernengo, M. (abril, 2012). Retrato de un joven economista: La evolución de las opiniones de Raúl Prebisch sobre el ciclo económico y el dinero, 1919-1949. Revista de la CEPAL, 106, 7-21.

Pollock, D., Kerner, D. y Love, J. L. (2001). Entrevista inédita a Prebisch: logros y deficiencias de la CEPAL, Revista de la CEPAL, 75, 9-23. Recuperado de http:// repositorio.cepal.org/handle/11362/10770

Prebisch, R. (1991a). Estudios sobre la moneda. J. B. Justo. En G. Weimberg (supervisor) y M. Fernández-López (comp.), Raúl Prebisch: Obras, 1919-1948 (3a. ed., Buenos Aires, 1921) (t. I-18, pp. 56-60). Buenos Aires: Fundación Raúl Prebisch.

Prebisch, R. (1991b). Anotaciones sobre nuestro medio circulante. A propósito del último libro del Dr. Norberto Piñero. En G. Weimberg (supervisor) y M. FernáNDEZ-LóPEz (comp.), Raúl Prebisch: Obras, 1919-1948 (t. I-23, pp. 93-175). Buenos Aires: Fundación Raúl Prebisch.

Prebisch, R. (1944). Observaciones sobre los planes monetarios internacionales. El Trimestre Económico, 11(42), 185-208.

Prebisch, R. (1991c). El patrón oro y la vulnerabilidad económica de nuestros países. En G. Weimberg (supervisor) y M. FernÁNDEZ-LÓPEZ (comp.), Raúl Prebisch: Obras, 1919-1948 (t. III-107, pp. 228-248). Buenos Aires: Fundación Raúl Prebisch.

Prebisch, R. (1993). Los planes monetarios internacionales. En G. Weimberg (supervisor) y M. Fernández-LóPez (comp.), Raúl Prebisch: Obras, 1919-1948 (t. IV-125, pp. 94-112). Buenos Aires: Fundación Raúl Prebisch.

PRebisch, R. (1949). El desarrollo económico de la América Latina y algunos de sus principales problemas. El Trimestre Económico, 16(63), 347-431.

Reinhart, C. M. y Trebesch, C. (diciembre, 2015). The International Monetary Fund: 70 years of reinvention. NBER, Documento de trabajo núm. 21805. Recuperado de http://www.nber.org/papers/w21805

Stiglitz, J. (2002). El malestar en la globalización. Buenos Aires: Taurus.

Turrent, E. (2009). México en Bretton Woods. México: Banco de México.

Williams, J. H. (1920). Argentine international trade under inconvertible paper money, 18801900. Cambridge: Harvard University Press. La traducción abreviada de Prebisch está disponible en https://archive.org/stream/elcomerciointern00will_0/elcomerciointern00will_0_djvu.txt 
Williams, J. H. (1929). The theory of international trade reconsidered. The Economic Journal, 39(154), 195-209.

Williams, J. H. (1936). The adequacy of existing currency mechanisms under varying circumstances. The American Economic Review, 27(1) (Supplement, Papers and Proceedings of the Forty-Ninth Annual Meeting of the American Economic Association, marzo de 1937), 151-168.

Williams, J. H. (julio, 1943a). Currency stabilization: the Keynes and White Plans. Foreign Affairs. Recuperado de https://www.foreignaffairs.com/articles/ united-states/1943-07-01/currency-stabilization-keynes-and-white-plans

Williams, J. H. (1943b). La estabilización monetaria: Los planes de Keynes y White. El Trimestre Económico, 10(39(3)), 431-449. Recuperado de http://www.jstor.org/ stable/20854569

Williams, J. H. (enero, 1944a). Currency stabilization: American and British attitudes. Foreign Affairs. Recuperado de https://www.foreignaffairs.com/articles/ united-states/1944-01-01/currency-stabilization-american-and-british-attitudes

Williams, J. H. (1944b). The Postwar Monetary Plan. The American Economic Review, 34(1(2)), 372-384. Recuperado de http://www.jstor.org/stable/1818710

Williams, J. H. (1944c). Postwar monetary plans and other essays. Nueva York: Knopf.

Williams, J. H. (1944d). The Joint Monetary Plan. En J. H. Williams (1944c). Postwar monetary plans and other essays (pp. XI-XXXI). Nueva York: Knopf. 